\title{
Auditory rehabilitation in adults: results of a training program
}

\author{
Cristiane Bueno Sales ${ }^{1}$ \\ https://orcid.org/0000-0003-3143-7806 \\ Luciana Macedo de Resende ${ }^{1}$ \\ https://orcid.org/0000-0002-2004-2692 \\ Carlos Faria Santos Amaral ${ }^{1}$ \\ https://orcid.org/0000-0003-4551-8228
}

Universidade Federal de Minas Gerais, Faculdade de Medicina, Programa de Pós-Graduação em Ciências Aplicadas à Saúde do Adulto, Belo Horizonte, Minas Gerais, Brasil.

Conflict of interests: Nonexistent

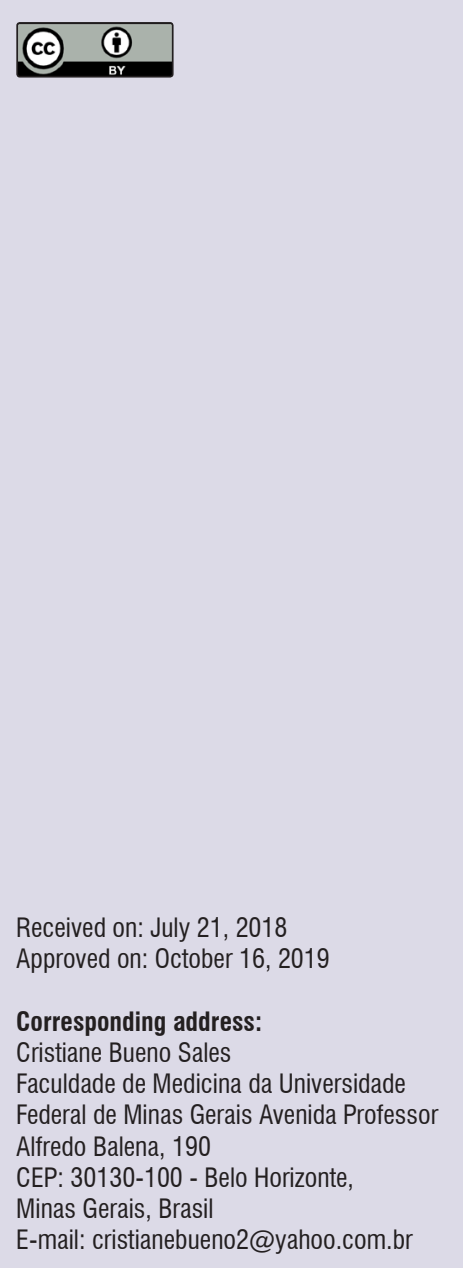

\section{ABSTRACT}

Objective: to describe the findings of the auditory processing behavioral tests in patients with hearing loss before and after hearing aid fitting associated with auditory training.

Methods: a descriptive analytical study that compared the findings of the auditory processing evaluation in 22 patients, from 19 to 62 years old, with mild or moderate sensorineural hearing loss. Tests used: Sound localization; Masking Level Difference; Alternate Disyllables Dichotic Listening Test; Melodic Frequency Pattern Test, Melodic Duration Pattern Test; Gaps in Noise; Speech in Noise Test. After the first tests, the patients were fitted with hearing aids and underwent eight auditory training sessions. The tests were retaken after a two-month period.

Results: there was a predominance of females and a moderate degree hearing loss. In the comparison of the initial and final assessment situations, a statistically significant difference $(p<0.05)$ was seen in all conditions studied, except for the Gaps in Noise and Masking Level Difference tests.

Conclusion: the results have proven that the auditory training performed in adult users of hearing aids brought about significant improvements on the auditory processing skills, thus, modifying their auditory behavior. The improvement of the results of the auditory processing behavioral tests in the initial and final situations reflects the hearing functional improvement achieved.

Keywords: Hearing Aids; Hearing; Hearing Loss; Correction of Hearing Impairment; Education of People with Hearing Disability 


\section{INTRODUCTION}

Among the human deficiencies, the auditory one may be considered one of the most devastating ailment as far as the person's social relations are concerned, resulting in the impairment of their capacity to communicate and interact with society ${ }^{1}$.

One of the ways to minimize the difficulties and disadvantages occurring as a consequence of such pathology is the use of the available technological resources, i.e., by means of fitting hearing aids (HAs) ${ }^{2}$.

Although the use of this device enables residual hearing to be stimulated, complaints related to auditory comprehension, even with the use of the hearing aids, are recurrent.

Recent researches make evident the importance of auditory training (AT) associated with the use of the HAs to promote effective prognosis ${ }^{3-5}$. One of the principles of auditory training is to develop neuroplasticity, in order to generate changes in auditory morphology and performance after hearing stimulation, making it possible for the patient to resignify each sound they hear. The tasks developed to improve auditory perception enable structural and functional changes to occur, and make the learning process easier ${ }^{6,7}$.

Subjects with the same degree and configuration of sensorineural hearing loss can present substantially different abilities regarding speech perception.

Basic audiological assessment quantifies the degree of hearing loss; however, it does not provide information on the preservation of auditory skills. The measurement of this information is possible only through the auditory processing (AP) behavioral tests 8,9 .

AP behavioral tests evaluate the processing of information via the sense of hearing, i.e., the integrative function of the nervous system, and the process of comparing a given sensorial experience with the one already stored or memorized ${ }^{10}$.

The early diagnosis, the indication of $\mathrm{HA}$ and its fitting, and a specific program of auditory reeducation to this population are fundamental to achieve better quality of life and, consequently, better family and social integration of the person with hearing disability ${ }^{11,12}$.

National researches ${ }^{4,13}$ describe the effectiveness of a formal auditory training program on elderly users of HA. The researches compared the results of an experimental group (submitted to the auditory training) with a control group (not submitted to the auditory training). Even though they had different objectives and methodologies, the authors were unanimous in concluding that the auditory training had shown to be effective in improving the auditory skills.

The individual values of the results of behavioral tests applied in researches using control groups may present great intersubject variability; this fact has been mentioned as a disadvantage when comparing groups of people. Some authors suggest that the individual be their own control, for this variability not to mask the true results ${ }^{14,15}$.

Other studies ${ }^{16,17}$ demonstrated the efficacy of auditory training in the rehabilitation of altered auditory skills in children diagnosed with auditory processing disorder, through the improvement of the results ofboth the behavioral measurements and the electrophysiological ones, as well as the continuance of the benefits obtained after the training, even one, two or three years after it had finished ${ }^{18}$.

In the case of loss of auditory sensitivity caused by auditory deficiency, modifications occur in the neural system up to the auditory cortex. The auditory cortex reorganization ability continues throughout life and reflects the ability to acquire new skills and behaviors ${ }^{19,20}$.

The interest for the study of behavioral tests for the assessment of auditory processing in individuals with hearing loss emerged from the observation, through clinical practice, of the constant complaint of difficulty in understanding speech on the part of these patients.

Studies describing the effectiveness of auditory rehabilitation programs with auditory fitting associated with auditory training are extremely important, since they provide the means for the establishment of public health policies and services specific for this population.

This study aimed at describing the findings of auditory processing behavioral tests in patients with hearing loss before and after the auditory fitting associated with auditory training.

\section{METHODS}

The research project was approved by the Ethics Committee of the Universidade Federal de Minas Gerais (Evaluation Report no. ETIC 0192.0.203.000 - 11).

This is an analytical descriptive study, in which the findings of the auditory processing behavioral tests of 22 patients, cared for at an Auditory Healthcare Service, who had mild or moderate post-lingual sensorineural hearing loss, were compared, both before and after fitting and auditory training.

For the selection of the sample, the following eligibility criteria were established: (1) age ranging 
from 18 to 65 years; (2) presenting diagnosis of mild to moderate degree of sensorineural hearing loss, according to Davis, 1970 (auditory threshold average of 30 to $55 \mathrm{~dB} H \mathrm{HL}$ at the frequencies of 500,1000 and 2000 $\mathrm{Hz}$ ); (3) presenting symmetrical hearing loss with flat or mildly sloping configuration in the high frequencies; (4) presenting speech recognition rates equal or superior to $72 \%$ bilaterally; (5) having the indication to use a hearing aid (HA); (6) not having previous experience with HA, i.e., never having used a HA before; (7) having Brazilian Portuguese as their first language; (8) after auditory fitting, making systematic and effective use of the electronic device, i.e., using it for eight hours a day or more; (9) having attended weekly the eight auditory training sessions, without interrupting the training; (10) having performed all auditory processing behavioral tests proposed by the study, before and after auditory rehabilitation.

The patients included in the Auditory Healthcare Program, referred for auditory evaluation and fitting in a six-month period, having met the inclusion criteria, were invited to participate in the study. The patients who agreed were included subsequently to signing the ICF.

The research began with 56 patients. However, 34 participants were excluded from the study because they had not used the HA for at least eight hours a day, or had not attended the auditory training sessions.

All the patients were submitted to the auditory processing behavioral assessment before HA fitting. The responses were recorded in specific protocols, and the number of right answers was analyzed according to the standardization norm for each test.

This paper researched all the mechanisms involved in auditory processing behavioral assessment of the four major functional categories proposed in the literature (monotic, dichotic, binaural interaction, and temporal processing) in the attempt to encompass the auditory skills necessary for speech perception and comprehension.

The chosen tests can be applied to patients with hearing loss, with three-tone average values of up to 55 $\mathrm{dB}$ for the frequencies of $500 \mathrm{~Hz}, 1000 \mathrm{~Hz}$, and 2000 $\mathrm{Hz}$. The reference values are the same of those used in individuals with auditory thresholds within standards of normality.

The battery of evaluations included the binaural interaction tests: Sound Localization - SL, and Masking Level Difference - MLD (Auditec St. Louis); dichotic test: Staggered Spondaic Word - SSW test; temporal processing tests: Melodic Frequency Pattern Test FPT (Taborja-Lizarro, 1999); Melodic Duration Pattern Test - DPT (Taborja-Lizarro, 1999); and, Gaps in Noise - GIN (Auditec St. louis); monotic test: Speech in Noise - SN.

The general characteristics of the behavioral tests applied to the patients in this study are described in Figure 1, according to target stimulus, listening task, functional category, assessed auditory skill, planned task, intensity of stimulus presentation, and criteria of normality. 


\begin{tabular}{|c|c|c|c|c|c|c|c|}
\hline Test & Stimulus & Listening task & $\begin{array}{c}\text { Functional } \\
\text { category }\end{array}$ & Auditory skill & Planned task & $\begin{array}{c}\text { Intensity } \\
\text { ofstimulus } \\
\text { presentation }\end{array}$ & $\begin{array}{l}\text { Criteria of } \\
\text { normality for } \\
\text { adults }\end{array}$ \\
\hline $\begin{array}{l}\text { Sound } \\
\text { Localization in } \\
\text { five directions }\end{array}$ & $\begin{array}{c}\text { Nonverbal } \\
\text { (sounding } \\
\text { object) }\end{array}$ & Dichotic & $\begin{array}{l}\text { Binaural } \\
\text { interaction }\end{array}$ & $\begin{array}{c}\text { Sound } \\
\text { Iocalization }\end{array}$ & $\begin{array}{l}\text { Localization and } \\
\text { lateralization } \\
\text { of the auditory } \\
\text { stimulus }\end{array}$ & & $\begin{array}{l}\text { Getting } 4 \text { or } 5 \\
\text { stimuli right, } \\
\text { as long as the } \\
\text { R and the L } \\
\text { are correctly } \\
\text { identified }\end{array}$ \\
\hline MLD & $\begin{array}{l}\text { Nonverbal (white } \\
\text { noise; pure- } \\
\text { tone) }\end{array}$ & Dichotic & $\begin{array}{l}\text { Binaural } \\
\text { interaction }\end{array}$ & $\begin{array}{l}\text { Binaural fusion; } \\
\text { auditory closure; } \\
\text { selective } \\
\text { attention, and } \\
\text { figure-ground. }\end{array}$ & $\begin{array}{c}\text { Detection of } \\
\text { the signal in } \\
\text { the presence of } \\
\text { noise. }\end{array}$ & $\begin{array}{c}50 \mathrm{~dB} \\
\text { SLabovethe } \\
\text { three-tone } \\
\text { average for } \\
500 \mathrm{~Hz}, 1000 \mathrm{~Hz} \\
\text { and } 2000 \mathrm{~Hz}\end{array}$ & $\begin{array}{l}\text { Equal to or } \\
\text { greater than } \\
9 \mathrm{~dB}\end{array}$ \\
\hline SSW & Verbal (words) & Dichotic & Dichotic & $\begin{array}{l}\text { Binaural analysis/ } \\
\text { synthesis; figure- } \\
\text { groundforverbal } \\
\text { sounds. }\end{array}$ & $\begin{array}{l}\text { Dichotic } \\
\text { listening; } \\
\text { binaural } \\
\text { integration and } \\
\text { sequencing }\end{array}$ & $\begin{array}{c}50 \mathrm{~dB} \\
\text { SLabovethe } \\
\text { three-tone } \\
\text { average for } \\
500 \mathrm{~Hz}, 1000 \mathrm{~Hz} \\
\text { and } 2000 \mathrm{~Hz}\end{array}$ & $\begin{array}{l}\text { Right answers } \\
\text { above } 90 \% \text { in } \\
\text { both ears }\end{array}$ \\
\hline $\begin{array}{c}\text { Duration Pattern } \\
\text { Test }\end{array}$ & $\begin{array}{c}\text { Nonverbal } \\
\text { (melodic tone) }\end{array}$ & Monotic & $\begin{array}{l}\text { Temporal } \\
\text { processing }\end{array}$ & $\begin{array}{l}\text { Temporal } \\
\text { ordering; } \\
\text { duration patterns } \\
\text { recognition; } \\
\text { differentiation } \\
\text { of sequential } \\
\text { sounds. }\end{array}$ & $\begin{array}{l}\text { Processing of } \\
\text { two or more } \\
\text { stimuli in a } \\
\text { specific ordering } \\
\text { to occur in time. }\end{array}$ & $\begin{array}{l}50 \mathrm{~dB} \text { SL above } \\
\text { the three-tone } \\
\text { average for } \\
500 \mathrm{~Hz}, 1000 \mathrm{~Hz} \\
\text { and } 2000 \mathrm{~Hz}\end{array}$ & $\begin{array}{l}100 \% \text { of right } \\
\text { answers in both } \\
\text { ears for the } \\
\text { sequence of } \\
\text { three sounds }\end{array}$ \\
\hline $\begin{array}{l}\text { Frequency } \\
\text { Pattern Test }\end{array}$ & $\begin{array}{c}\text { Nonverbal } \\
\text { (melodic tone) }\end{array}$ & Monotic & $\begin{array}{l}\text { Temporal } \\
\text { processing }\end{array}$ & $\begin{array}{l}\text { Temporal } \\
\text { ordering; } \\
\text { frequency } \\
\text { patterns } \\
\text { recognition; } \\
\text { differentiation } \\
\text { of sequential } \\
\text { sounds. }\end{array}$ & $\begin{array}{l}\text { Processing of } \\
\text { two or more } \\
\text { stimuli in a } \\
\text { specific ordering } \\
\text { to occur in time. }\end{array}$ & $\begin{array}{c}50 \mathrm{~dB} \\
\text { SLabovethe } \\
\text { three-tone } \\
\text { average for } \\
500 \mathrm{~Hz}, 1000 \mathrm{~Hz} \\
\text { and } 2000 \mathrm{~Hz}\end{array}$ & $\begin{array}{l}\text { Over } 70 \% \text { of } \\
\text { right answers } \\
\text { in both ears for } \\
\text { the sequence of } \\
\text { three sounds }\end{array}$ \\
\hline GIN & $\begin{array}{c}\text { Nonverbal (white } \\
\text { noise) }\end{array}$ & Monotic & $\begin{array}{l}\text { Temporal } \\
\text { processing }\end{array}$ & $\begin{array}{l}\text { Temporal } \\
\text { resolution; } \\
\text { distinction of the } \\
\text { interval between } \\
\text { stimuli. }\end{array}$ & $\begin{array}{l}\text { Minimum time } \\
\text { required for } \\
\text { segregating or } \\
\text { solving acoustic } \\
\text { events. }\end{array}$ & $\begin{array}{c}50 \mathrm{~dB} \\
\text { SLabovethe } \\
\text { three-tone } \\
\text { average for } \\
500 \mathrm{~Hz}, 1000 \mathrm{~Hz} \\
\text { and } 2000 \mathrm{~Hz}\end{array}$ & $\begin{array}{c}\text { threshold of } 5 \text { to } \\
6 \mathrm{~ms}\end{array}$ \\
\hline Speech in Noise & $\begin{array}{l}\text { Verbal (words); } \\
\text { competitive } \\
\text { white noise }\end{array}$ & Monotic & Monotic & $\begin{array}{l}\text { Figure-ground; } \\
\text { closure for verbal } \\
\text { sounds. }\end{array}$ & $\begin{array}{l}\text { Recognize } \\
\text { physically- } \\
\text { distorted } \\
\text { verbal sounds } \\
\text { presented to an } \\
\text { ear at a time. }\end{array}$ & $\begin{array}{c}40 \mathrm{~dB} \\
\text { SLabovethe } \\
\text { three-tone } \\
\text { average for } \\
500 \mathrm{~Hz}, 1000 \mathrm{~Hz} \\
\text { and } 2000 \mathrm{~Hz} \\
\text { Main message/ } \\
\text { competitive } \\
\text { message relation } \\
\text { of }+15 \mathrm{~dB} \\
\end{array}$ & $\begin{array}{l}\text { Over } 70 \% \text { of } \\
\text { right answersin } \\
\text { both ears }\end{array}$ \\
\hline
\end{tabular}

Legend: MLD (Masking Level Difference), SSW (Staggered Spondaic Word), GIN (Gaps in Noise).

Figure 1. Classification of the auditory processing behavioral assessment tests according to target stimulus, listening task, functional category, assessed auditory skill, planned task, intensity of stimulus presentation, and criteria of normality 
For the analysis of the SSW test, whose planned task is of dichotic listening, binaural integration, and sequencing, the analysis of the quantitative results was chosen for this study, describing the general results of the right and left ears, presenting the sum of right answers in the noncompetitive conditions (Right Noncompetitive and Left Noncompetitive), and in the competitive conditions (Right Competitive and Left Competitive).

All the patients who participated in the study had never used HA before. Thus, they underwent the first battery of behavioral tests without any previous HA experience. The time of sensorial deprivation could not be measured in this study, as many participants were not able to state how old they were when they began to notice their hearing loss.

After the first battery of behavioral tests carried out prior to auditory fitting, the patients were fitted with HA bilaterally and were referred to speech-languagehearing therapy sessions. The term "auditory fitting" refers to the first moment when the patient was first fitted with the hearing aids, after the time of sensorial deprivation.

The stage of auditory training was organized in eight individual 60-minute sessions, conducted once a week.

The auditory training (AT) proposed in this study was conducted through the use of the Escutação ${ }^{21}$ instrument, composed of 76 auditory stimulation tracks, with activities working especially the auditory skills of vigilance, sound localization, auditory differentiation, association, integration, and temporal processing.

The 76 activities were distributed throughout the eight auditory training sessions, adding up to nine tracks being used in each of the four first sessions of the first month, while the four remaining sessions of the second month were composed of ten stimulation tracks each.

The acoustic tracks of the Escutação material propose the auditory stimulation of the right and left ears separately, making it impossible for the auditory training to be performed in sound field. The auditory training was conducted without the hearing aids and with the use of stereo earphones. Nevertheless, the proposed activities were performed in sufficiently audible intensity so as to ensure audibility to the patients with hearing loss during the auditory stimulation.

The main strategies developed throughout the auditory training are described in Figure 2.

After eight weeks of AT, all the specific auditory processing exams taken previously were reassessed, also following the same criteria adopted before the therapeutic intervention. The final evaluations of the auditory processing behavioral tests were conducted without the use of the HA, as they had been conducted in the initial evaluations.

The procedures performed with the patients included in the study are described in the flowchart (Figure 3). 


\begin{tabular}{|c|c|}
\hline Stimulated auditory skills & $\begin{array}{l}\text { Objectives / Strategies } \\
\end{array}$ \\
\hline Vigilance skill & $\begin{array}{l}\text { - To favor attention to speech to the detriment of environment sounds; } \\
\text { - } \quad \text { To promote concentrationon a specific stimulus, ignoring the noise (figure-ground); } \\
\text { - } \quad \text { To provideauditory differentiation and directed listening. }\end{array}$ \\
\hline Sound source localization skill & $\begin{array}{l}\text { - To identify the direction of origin of a sound; } \\
\text { - } \quad \text { Auditory attention; } \\
\text { - } \quad \text { Vigilance. }\end{array}$ \\
\hline Differentiation skill & $\begin{array}{l}\text { - To differentiate and recognize similarities and differences between sounds, seeking for their } \\
\text { meaning based on the analysis and synthesis of the speech sounds received; } \\
\text { - To develop phonological conscience; } \\
\text { - } \quad \text { Auditory closure. }\end{array}$ \\
\hline Association skill & $\begin{array}{l}\text { - To develop the coding process, i.e., to determine the meaning of the information received; } \\
\text { - To enablethe person to perceive parts of auditory information, and analyze them, giving them a } \\
\text { meaning, thus making comprehension possible. }\end{array}$ \\
\hline Integration skill & $\begin{array}{l}\text { - To favor the capacity of the person to hear sets of sounds and connect them to other sensorial } \\
\text { information so as to give meaning to a message or task; } \\
\text { - Auditory comprehension - "getting the general idea"; } \\
\text { - Multisensorial strategies - the integration skills reflect the connections of the person's sensory } \\
\text { centers - hearing, sight, touch, taste and smell. }\end{array}$ \\
\hline Temporal processing skill & $\begin{array}{l}\text { - To stimulate the capacity of following sequences, organizing and registering what is heard. } \\
\text { - To promote the skills of temporal resolution, temporal ordering, and naming of quick sounds in } \\
\text { succession, differing in duration, frequency and intensity aspects of the sounds as time passes. }\end{array}$ \\
\hline
\end{tabular}

Figure 2. Objectives and strategies of the auditory training sessions

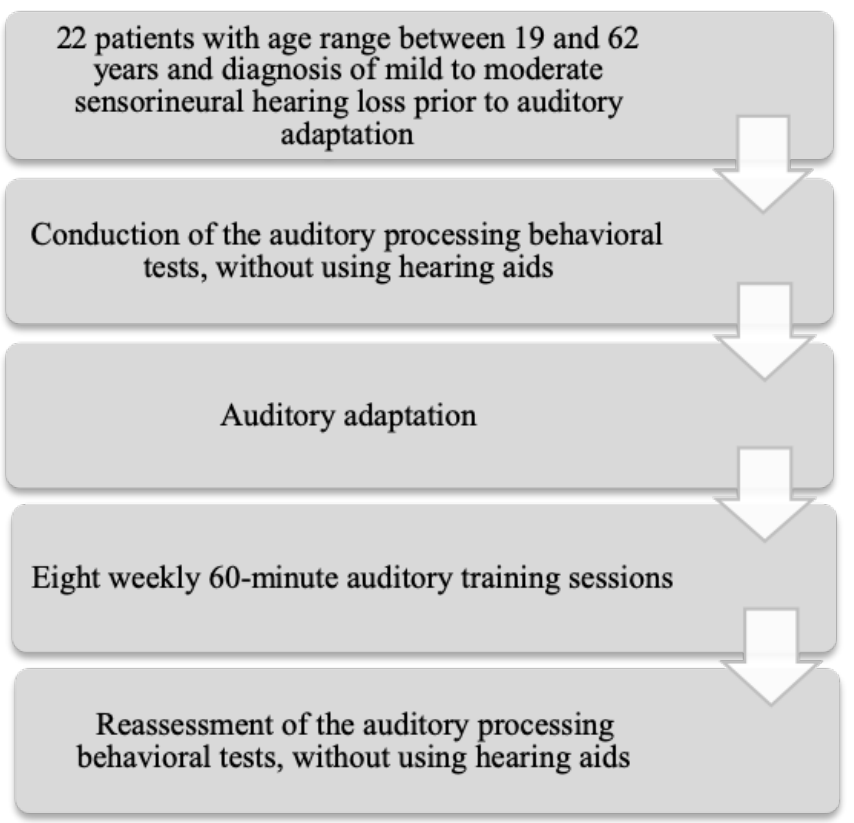

Figure 3. Flowchart of the stages of the study
All the examining and auditory training procedures were conducted in a sound booth, and for the development of the research, the following equipment and material were used: two-channel audiometer, Madsen brand, model Midimate 602, furnished with TDH-39 earphones, calibrated in compliance with the ISO8253-1 norm (1989); compact disc (CD) with the following tests recorded on it: Staggered Spondaic Word (SSW), Melodic Frequency Pattern Test (FPT), Taborja-Lizarro, 1999, Melodic Duration Pattern Test (DPT), Taborja-Lizarro, 1999, and Speech in Noise (SN), an integral part of the book Pereira LD, Schochat E. Testes Auditivos Comportamentais Para Avaliação Do ProcessamentoAuditivo Central (Auditory Behavioral Tests for the Evaluation of the Central Auditory Processing). Editora Pró-Fono; Barueri, 2011; compact disc (CD) Auditec, St Louis, with the recordings of the Masking Level Difference (MLD) andGaps In Noise (GIN) tests; Guizo II instrument for conducting the Sound Localization Test; mini sound system, Philips brand, model Soundmachine AZ 1133, with direct output to the audiometer; and, the book by Gielow, I. Escutação. Editora TT Thot; São Paulo, 2008, including two CDs with the recordings used for the auditory training. 


\section{Statistical analysis}

This was a pilot study; hence no sample calculation was done. The statistical analysis was carried out with the use of SPSS statistical software (SPSS Inc., Chicago, Illinois), version 17.0.

The Kolmogorov-Smirnov test was used to verify the normality of distribution of variables. Once these do not have normal distribution, the continuous variables were expressed as median and interquartile range (IQR), and the analysis of the outcomes was carried out using the Wilcoxon signed rank paired test.

The significance level of $5 \%$ was adopted, and all the $p$-values were two-tailed.

\section{RESULTS}

The main characteristics of the 22 patients assessed in this study are described in Table 1. The sample was composed of 22 patients aged from 19 to 62 years, median of 54.50 years, interquartile range (IQR) 42.75 59.00; 17 (77\%) were female, and five (23\%) were male. As for schooling, 13 patients $(59.09 \%)$ had incomplete Middle School.

Regarding the degree of hearing loss, there was a predominance of moderate bilateral, $73 \%$ of them on right ear $(\mathrm{N}=16)$, and $64 \%$ on the left ear $(\mathrm{N}=14)$.

As for the configuration of the audiometric curve, the mildly sloping curve was the most frequent, both on the RE and on LE (64\%).

Table 1. Characteristics of the participants in the study

\begin{tabular}{|c|c|c|}
\hline Characteristics & $\mathbf{N}$ & $\%$ \\
\hline \multicolumn{3}{|l|}{ Gender } \\
\hline Females & 17 & 77.00 \\
\hline Males & 5 & 23.00 \\
\hline \multicolumn{3}{|l|}{ Age } \\
\hline 19 years - 29 years & 1 & 4.55 \\
\hline 30 years- 39 years & 3 & 13.64 \\
\hline 40 years- 49 years & 5 & 22.73 \\
\hline 50 years- 62 years & 13 & 59.09 \\
\hline \multicolumn{3}{|l|}{ Schooling } \\
\hline Incomplete Middle School & 13 & 59.09 \\
\hline Complete Middle School & 1 & 4.55 \\
\hline Incomplete High School & 3 & 13.64 \\
\hline Complete High School & 3 & 13.64 \\
\hline Incomplete Higher Education & 1 & 4.55 \\
\hline Complete Higher Education & 1 & 4.55 \\
\hline \multicolumn{3}{|c|}{ Degree of Hearing Loss on the Right Ear } \\
\hline Mild & 6 & 27.00 \\
\hline Moderate & 16 & 73.00 \\
\hline \multicolumn{3}{|c|}{ Degree of Hearing Loss on the Left Ear } \\
\hline Mild & 8 & 36.00 \\
\hline Moderate & 14 & 64.00 \\
\hline \multicolumn{3}{|c|}{ Audiometric Configuration of the Right Ear } \\
\hline Horizontal & 8 & 36.00 \\
\hline Mildly sloping & 14 & 64.00 \\
\hline \multicolumn{3}{|c|}{ Audiometric Configuration of the Left Ear } \\
\hline Horizontal & 8 & 36.00 \\
\hline Mildly sloping & 14 & 64.00 \\
\hline
\end{tabular}


The values described in the Tables 2, 3, 4 and 5 present the patients' results in the pre-rehabilitation situation (initial assessment) and after the auditory rehabilitation (final assessment)

Table 2 describes the median and interquartile range values of the binaural interaction tests. For the test of sound localization, the results of the number of right answers are presented in absolute values. The increase of these numbers on the final assessment in relation to the initial one is noticeable, with significant difference. On the MLD test, the thresholds of the evaluation are expressed in absolute values. An improvement on the thresholds for each condition studied can be observed, though without significant difference between the initial and the final assessments.

Table 2. Descriptive measurements of the binaural interaction tests on the initial and final assessments - Sound Localization and Masking Level Difference (MLD)

\begin{tabular}{cccc}
\hline & & Median & p-value \\
\hline \multirow{2}{*}{ Sound Localization* } & Initial & $3.00(3.00-4.00)$ & $0.019^{*}$ \\
& Final & $4.00(3.75-5.00)$ & $0.269^{*}$ \\
\hline \multirow{2}{*}{ MLD** } & Initial & $0.00(0.00-10.00)$ & $6.00(1.50-10.00)$ \\
\hline
\end{tabular}

*Values expressed as median (interquartile range) of the number of right answers.

$* *$ Values expressed as median (interquartile range) in absolute number (threshold).

Legend: Masking Level Difference (MLD).

$p=$ probability of significance, Wilcoxon Signed Rank Test.

In Table 3, there is the percentage distribution of the results of the Staggered Spondaic Word (SSW) dichotic listening test on the right and left ears. A progress in the results of the final test in relation to the initial one on both ears, especially on the left, can be observed, with significant difference bilaterally.

Table 3. Measurements of the percentage of right answers on the dichotic listening test on the initial and final assessments - Staggered Spondaic Word (SSW) Test

\begin{tabular}{cccc}
\hline & & RE (\%) & LE (\%) \\
\hline \multirow{2}{*}{ SSW } & Initial & $68.75(48.12-78.75)$ & $75.62(60.62-90.31)$ \\
p-value & Final & $85.62(58.75-95.00)$ & $91.87(81.56-96.25)$ \\
\hline
\end{tabular}

Values expressed as median (interquartile range) in percentage (\%).

Results referring to the proportion of final right answers of the four listening conditions of the SSW test - CR: competitive right; CL: competitive left; NCR:

noncompetitive right; NCL: noncompetitive left.

Legend: Staggered Spondaic Word (SSW) Test; RE: Right Ear; LE: Left Ear.

$p=$ probability of significance, Wilcoxon Signed Rank Test.

The comparative results between the groups, in the situations of initial and final assessment, referring to the temporal processing tests, are in Table 4. The values of the duration pattern and frequency pattern tests are described in percentage distribution of right answers; as for the GIN threshold test, the values are in absolute numbers. There was statistically significant difference in all the conditions studied, except for the GIN threshold. 
Table 4. Measurements of the percentage of right answers on the temporal processing tests on the initial and final assessments Duration Pattern Test / Frequency Pattern Test / Gaps in Noise

\begin{tabular}{cccc}
\hline & & RE (\%) & LE (\%) \\
\hline DPT & Initial & $90.00(80.00-100.00)$ & $100.00(90.00-100.00)$ \\
p-value & Final & $100.00(90.00-100.00)$ & $100.00(100.00-100.00)$ \\
FPT & Initial & $0.010^{*}$ & $0.038^{*}$ \\
p-value & Final & $40.00(30.00-82.50)$ & $50.00(37.50-70.00)$ \\
*GIN Threshold & & $70.00(50.00-90.00)$ & $70.00(67.50-82.50)$ \\
p-value & Initial & $0.003^{*}$ & $0.000^{*}$ \\
\hline & Final & $4.00(00.00-10.00)$ & $4.00(00.00-10.50)$ \\
& & $4.50(4.00-6.00)$ & $6.00(4.00-8.00)$ \\
\end{tabular}

Values expressed as median (interquartile range) in percentage (\%).

*Values expressed as median (interquartile range), in absolute number (threshold) - milliseconds.

Legend: DPT - Duration Pattern Test; FPT - Frequency Pattern Test; GIN -Gaps In Noise; RE: Right Ear; LE: Left Ear

$p=$ probability of significance, Wilcoxon Signed Rank Test.

Concerning the monaural low-redundancy test used in the study (speech in noise), it was possible to notice an improvement in the comparison of the percentages on the two distinct assessment moments, with significant difference bilaterally (Table 5).

Table 5. Measurements of the percentage of right answers on the monaural low-redundancy test on the initial and final assessments Speech in Noise

\begin{tabular}{cccc}
\hline & & RE (\%) & LE (\%) \\
SN & Initial & $44.00(36.00-60.00)$ & $48.00(38.00-61.00)$ \\
p-value & Final & $72.00(64.00-84.00)$ & $70.00(63.00-84.00)$ \\
& & $0.000^{*}$ & $0.000^{*}$ \\
\hline
\end{tabular}

Values expressed as median (interquartile range) in percentage (\%).

Legend: SN - Speech in Noise; RE: Right Ear; LE: Left Ear.

$p=$ probability of significance, Wilcoxon Signed Rank Test.

\section{DISCUSSION}

The results presented here are in agreement with other epidemiologic studies $3,4,13,16,17$, which state that there is improvement on AP skills after auditory rehabilitation.

The tests used in this research are considered to be stable, proven in test-retest study ${ }^{22}$. Thus, changes in their responses suggest modifications on the auditory system and functions, as a consequence of the cell reorganization generated by the sound amplification, by auditory learning induced by training, or yet, by the natural maturation of the system ${ }^{19,23}$.

The sound localization test in five directions aims at seeking information on binaural interaction. The patients in this research presented responses below standards of normality in the initial test situation, which agrees with a study ${ }^{24}$ that evaluated the auditory behaviors of auditory closure, sound localization, and temporal resolution in individuals with unilateral hearing loss. These presented alterations on the auditory skill of sound localization, when compared to normal individuals, and presented worse performance on auditory closure and temporal resolution tasks. Nonetheless, on the final assessment, after the auditory rehabilitation proposed by this study, the individuals got four or five directions right, the right and the left being correctly identified; these results are considered as normal according to the reference criteria.

Another test investigating the auditory skill of binaural interaction is the Masking Level Difference (MLD), whose objective is to assess the abilities of auditory closure, figure-ground, and attention. 
Individuals exposed to noise, with and without hearing loss, were submitted to evaluation through the MLD test, and the comparison of the results obtained in the groups studied demonstrated that the performance of the subjects exposed to noise without hearing loss were inferior to the control group, though both obtained normal results. In the patients with hearing loss, the tests were below normality ${ }^{25}$. The same happened with the individuals in this study, whose performance on the MLD test was below the criteria for normality. It was possible to identify improvement on the thresholds for each condition studied, though without significant difference between the initial and final assessments.

Regarding dichotic listening, the quantitative results of the initial assessment of the cases studied are below standards of normality, bilaterally. The results in percentage of the left ear were better than those of the right ear. Progress of the results on the final assessment in relation to the initial was observed, with significant difference bilaterally.

Other researchers found results quite similar to the ones obtained in this study. A research ${ }^{26}$ compared $^{-}$ the performance of patients with bilateral sensorineural hearing loss, both users and nonusers of $\mathrm{HA}$, through the SSW test of dissyllable recognition in dichotic task. The group of users presented better performance on the conditions studied than the group of nonusers, especially on the competitive conditions. The results obtained pointed to the efficacy of the use of the HA in improving speech comprehension of the population studied.

Another study ${ }^{27}$ compared the performance of elderly on dichotic listening tests at the moment of auditory fitting, after a month of use of this device, and after the auditory training. All the participants gradually increased their scores on the auditory processing tests, obtaining better performance after the auditory training; the comparison between the three moments was statistically significant.

The comparison of the temporal auditory processing performance between elderly people with and without hearing loss was studied ${ }^{28}$. The groups performed the frequency and duration pattern tests to assess the ability of sequencing and temporal ordering, and the Random Gap Detection Test (RGDT) to assess the ability of temporal resolution. There was no significant difference on temporal auditory processing in the comparison between the groups.

With the objective of studying temporal processing in this research, the Frequency Pattern Test (FPT) and the Duration Pattern Test (DPT) were used to assess the temporal ordering, and the Gaps in Noise (GIN) test, to assess temporal resolution.

In this study, all the tests used to evaluate temporal auditory processing were below the standards of normality on the initial assessment. However, there was significant improvement on the comparative results on the final assessment, except for the GIN threshold.

These findings agree with those found in a study ${ }^{29}$ that compared the auditory behavior of temporal resolution in individuals with symmetrical and asymmetrical sensorineural hearing loss, as well as individuals with cerebral lesion, and normal individuals. The tests used were the RGDT and GIN. The skill of temporal resolution was similar between the group of individuals with symmetrical hearing loss and the group with cerebral lesion. Both groups presented worse performance than the control group.

Given the importance of the temporal aspects for the maximization of the abilities of auditory processing, the significant improvement observed on the initial and final assessments may have fundamental importance for the improvement on the communication of patients using HA, especially in adverse hearing environments.

The effects of hearing loss on speech perception in the presence of noise were investigated ${ }^{9}$. The results demonstrated that noise interferes negatively with speech recognition in individuals with and without hearing loss. Nevertheless, the performance of the subjects with normal hearing was superior to the group with hearing loss.

Regarding the monotic test used in the study (Speech in Noise), it was possible to observe an improvement on the comparison of the percentages at the two distinct assessment moments, with significant difference bilaterally. Other studies ${ }^{3,13,18,30}$ also demonstrated the effectiveness of the auditory rehabilitation on the results of the abilities of figure-ground and auditory closure for verbal sounds.

The isolated use of hearing aids may not bring the benefits expected to minimize the effects caused by the sensorial losses, in spite of the significant technological advances in the digital era. A study ${ }^{31}$ described that speech recognition in the presence of noise is one of the main complaints of the people with hearing disability. And, even though technology may partially solve some hearing problems, auditory training is the alternative to improve auditory performance in noise, and the satisfaction with the use of the electronic devices. The literature underlying auditory plasticity 
after $\mathrm{HA}$ fitting suggests that additional auditory training may be necessary for "cortical reorganization" to occur.

The results of this study revealed the improvement on the auditory skills necessary to interpret sound auditory patterns with the global auditory rehabilitation. The improvement on the results of AP behavioral test in the initial and final situations reflects auditory functional improvement.

In a systematic review ${ }^{32}$, the authors investigated whether the improvements on the trained skills remain after auditory training has finished (learning retention). All the studies presented demonstrated learning retention of trained skills in various degrees, with only some reporting the statistical effects.

Studies revealed that auditory rehabilitation is important for adults and elderly, since it may lead to benefits on auditory capacity, short- and long-term memory, learning skills, cognitive performance skills, and depressive aspects, in addition to improving communication as a whole, seen as a more elaborate function than hearing itself ${ }^{33}$.

The HA fitting alone may furnish enough audibility for the perception of speech sounds; however, global auditory rehabilitation, associated with the use of HA and the AT, can potentialize the capacity to process sounds, and optimize the skills involved in the auditory processing. Hence, it is expected that the patient be better prepared to face day-to-day situations, using the $\mathrm{HA}$ in its potentiality and at last culminating in a more adequate social integration.

The importance of routinely indicating auditory processing behavioral assessments at Auditory Healthcare Services is noted, as well as the association between HA fitting and the auditory skills training, regardless of the patient's age, so as to make possible the decrease of auditory difficulties, and the improvement of the quality of life.

\section{CONCLUSION}

The results of this study proved that HA fitting associated with auditory training in adult patients resulted in significant improvement of the auditory processing skills, changing the auditory behavior. The improvement on the results of the AP behavioral tests in the initial and final situations reflects the auditory functional improvement accomplished.

\section{REFERENCES}

1. Silman S, lório MCM, Mizhahi MM, Parra VM. Próteses auditivas: um estudo sobre seu benefício na qualidade de vida de indivíduos portadores de perda auditiva neurossensorial. Distúrb. Comun. 2004;16(2):153-65.

2. Kozlowski L, Ribas A, Almeida G, Luz I. Satisfaction of elderly hearing aid users. Int Arch Otorhinolaryngol. 2017;21(1):92-6.

3. Beier LO, Pedroso F, Costa-Ferreira MID. Auditory training benefits to the hearing aids users - a systematic review. Rev. CEFAC. 2015;17(4):1327-32.

4. Megale RL, lorio MCM, Schochat E. Treinamento auditivo: avaliação do benefício em idosos usuários de prótese auditiva. Pró-Fono $\mathrm{R}$ Atual. Cient. 2010;22(2):101-6.

5. Teixeira AR, Thedy RB, Jotz GP, Barba MC. Sintomatologia depressiva em deficientes auditivos adultos e idosos: importância do uso de próteses auditivas. Arquivos Int Otorrinolaringol. 2007;11(4):453-8.

6. Katz J, Stecker NA, Henderson D. Central auditory processing: a transdiciplinary view. Saint Louis, Mosby Year Book; 1992.

7. ASHA - American Speech-Language-Hearing Association. Task force on central auditory processing consensus development: central auditory current status of research and implications for clinical practice. J Am Acad Audiol. 1996;5(2):41-54.

8. Arlinger S. Negative consequences of uncorrected hearing loss - a review. Int $\mathrm{J}$ Audiol. 2003;42(2):17-20.

9. Caporali AS, Silva JA. Reconhecimento de fala no ruído em jovens e idosos com perda auditiva. Rev Bras Otorrinolaringol. 2004;70(4):525-32.

10. Pereira LD, Schochat E. Testes auditivos comportamentais para avaliação do Processamento Auditivo Central. Barueri: Pró-Fono; 2011.

11. Silva LSG, Gonçalves CGO, Soares VMN. National Policy on Health Care Hearing: an evaluative study from covering services and diagnostic procedures. CoDAS. 2014;26(3):241-7.

12. Mattos LC, Veras RP. A prevalência da perda auditiva em uma população de idosos da cidade do Rio de Janeiro: um estudo seccional. Rev Bras Otorrinolaringol. 2007;73(5):654-9.

13. Miranda EC, Andrade NA, Gil D, lório MCM. A efetividade do treinamento auditivo formal em 
idosos usuários de próteses auditivas no período de aclimatização. Rev Soc Bras Fonoaudiol. 2007;12(4):316-21.

14. Tremblay KL, Kraus N. Auditory training induces asymmetrical changes in cortical neural activity. J Speech Lang Hear Res. 2002;45(3):564-72.

15. Russo NM, Nicol TG, Zecker SG, Ilayes EA, Kraus $\mathrm{N}$. Auditory training improves neural timing in the human brainstem. Behavioral Brain Research. 2005;156(1):95-103.

16. Alonso $\mathrm{R}$, Schochat $\mathrm{E}$. A eficácia do treinamento auditivo formal em crianças com transtorno de processamento auditivo (central): avaliação comportamental e eletrofisiológica. Braz J Otorhinolaryngol. 2009;75(5):726-32.

17. Silva TR, Dias FAB. Effectiveness of training auditory in plasticity of central auditory system: case report. Rev. CEFAC. 2014;16(4):1361-9.

18. Filippini R, Brito NFS, Neves-Lobo IF, Schochat E. Maintenance of auditory abilities after auditory training. Audiol Commun Res. 2014;19(2):112-6.

19. Musiek FE, Shinn JMS, Hare CMA. Plasticity, auditory training and auditory processing disorders. Seminars in Hearing. 2002;23(4):263-75.

20. Grieco-Calub TM, Ward KM, Kristina M, Brehm L. Multitasking during degraded speech recognition in school-age children. Trends in Hearing. 2017;21(3):1-14.

21. Gielow l. Escutação. Editora Thot; São Paulo, 2008.

22. Frascá MFSS, Neves-Lobo IF, Schochat E. Processamento auditivo em teste e reteste: confiabilidade da avaliação. Rev Soc Bras Fonoaudiol. 2011;16(1):42-8.

23. Fell AC, Teixeira AR. Cognição em idosos: influência do uso de aparelhos de amplificação sonora individual. Rev Kairós Gerontologia. 2015;18(2):197-208.

24. Nishihata R, Vieira MR, Pereira LD, Chiari MB. Temporal processing, localization and auditory closure in individuals with unilateral hearing loss. Rev Soc Bras Fonoaudiol. 2012;17(3):266-73.

25. Ubrig MT, Barreiro FCAB. Investigação da habilidade auditiva central de interação binaural em metalúrgicos com e sem perda auditiva. Distúrb. Comunic. 2003;15(2):253-64.

26. Freitas MS, Naves K, Frizzo ACF, Gonçales AS. Assessing individuals with bilateral hearing loss users and non-users of hearing aids by the SSW test. Rev. CEFAC. 2013;15(1):69-78.
27. Fonseca GCR, Costa-Ferreira MID. The performance of the elderly with neurosensorial hearing loss in auditory processing tests: a longitudinal study. Rev. CEFAC. 2015;17(3):809-18.

28. Azzolini VC, Ferreira MIDC. Temporal auditory processing in elders. Arq Int Otorrinolaringol. 2010;14(1):95-102.

29. Gallo J. Temporal resolution on sensorineural hearing loss and brain lesions. Rev Soc Bras Fonoaudiol. 2012;17(4):505.

30. Teixeira TS, Costa-Ferreira MID. Treinamento auditivo computadorizado em idosos protetizados pelo Sistema Único de Saúde. Audiol Commun Res. 2018;23:e1786.

31. Olson $A D$. Options for auditory training for adults with hearing loss. Semin Hear. 2015;36(4):284-95.

32. Ferguson $M$, Henshaw $H$. How does auditory training work? Joined-up thinking and listening. Semin Hear. 2015;36(4):237-49.

33. Castiglione A, Benatti A, Velardita C, Favaro D, Padoan E, Pagliaro $\mathrm{M}$ et al. Aging, cognitive decline and hearing loss: effects of auditory rehabilitation and training with hearing aids and cochlear implants on cognitive function and depression among older adults. Audiol Neurotol. 2016;21(1):21-8. 